Área Abierta. Revista de comunicación

audiovisual y publicitaria

ISSN: 2530-7592 / ISSNe: 1578-8293

https://dx.doi.org/10.5209/arab.75638

\title{
La estética del género ciberpunk como filosofía de la historia: un recorrido por las arquitecturas fílmicas de Alphaville, Blade Runner y Matrix y su ruptura del espacio-tiempo
}

\author{
Julio Pérez Manzanares ${ }^{1}$ y Amaia Zufiaur Ruiz de Eguino ${ }^{2}$
}

Recibido: 24 de abril de 2021 / Aceptado: 20 de septiembre de 2021

Resumen. La aparición del género ciberpunk coincide con los inicios de la denominada posmodernidad. En el presente artículo, y siguiendo las críticas que se han venido realizando de la misma como momento de cambio de paradigma histórico, proponemos el análisis de los espacios profílmicos de la ficción como campo de investigación en el que se sintetizan las preocupaciones de una fenomenología propia del "fin de los tiempos". Observando los ejemplos que han ido configurando el género cinematográfico hasta darle entidad propia, trataremos de explicar algunas de sus características estéticas — como las distopías temporales, la combinación de tiempos históricos o la tendencia a la cita y el pastiche- como reflejo e investigación de preocupaciones propias del momento relacionadas con discusiones propias de la filosofía de la historia y de los medios, así como de la importancia actual de la ficción como método para pensar la historia y analizar las categorías temporales.

Palabras clave: Ciberpunk; Historia; Distopía; Espacio Profílmico; Posmodernidad

\section{[en] The Aesthetics of the Cyberpunk Genre As a Philosophy of History: A Journey Through the Film Architectures of Alphaville, Blade Runner and Matrix, and Their Rupture of Space-Time}

\begin{abstract}
The appearance of the cyberpunk genre coincides with the beginnings of the so-called postmodernity. In this article, and following the criticisms that have been made of it as a moment of change in the historical paradigm, we propose the analysis of the profilmic spaces of fiction as a field of research in which the concerns of a phenomenology of the "end of temporality" are synthesized. Taking account of the most significant examples that have been shaping the cinematographic genre to the point of bestowing it its own entity, we will try to explain some of its aesthetic characteristics - such as temporal dystopias, the combination of historical times or the tendency to quote and pastiche - as a reflection and investigation of concerns and discussions related to philosophy of history and the media. In doing so, we will try to face the current importance of fiction as a method for thinking about history and analysing temporal categories.
\end{abstract}

Keywords: Cyberpunk; History; Dystopia; Aesthetics; Profilmic Space; Accelerationism

1 Universidad Antonio de Nebrija (España).

E-mail: jperezman@nebrija.es

ORCID: https://orcid.org/0000-0003-0450-2932

2 Universidad Antonio de Nebrija (España).

E-mail: azufiaurr@alumnos.nebrija.es

ORCID: https://orcid.org/0000-0002-7720-3864 
Sumario. 1. Introducción. 2. Justificación del análisis profílmico y la representación temporal. 3. Historia, posmodernidad y utopía: el ciberpunk como filosofía histórica. 4. Conclusión: nuevos paradigmas estéticos, nuevos paradigmas históricos. 5. Bibliografía.

Cómo citar. Pérez Manzanares, Julio y Zufiaur Ruiz de Eguino, Amaia (2021). La estética del género ciberpunk como filosofía de la historia: un recorrido por las arquitecturas fillmicas de Alphaville, Blade Runner y Matrix y su ruptura del espacio-tiempo. Área Abierta. Revista de comunicación audiovisual y publicitaria 21 (3), 419-435, https://dx.doi.org/10.5209/arab.75638

\section{Introducción}

Dentro de las discusiones que han rodeado a la denominada posmodernidad y sus manifestaciones estéticas, una de las más relevantes ha sido aquella que ha recurrido a la representación del propio tiempo desde la nueva perspectiva de la época. El propósito de este artículo trata de analizar el espacio profílmico de algunas de las producciones audiovisuales más definitivas de la época, en las que el propio tiempo y su representación se convirtieron tanto en reflejo como en investigación de esta nueva temporalidad. Aquellas que, genéricamente, han venido a denominarse ciberpunk. Analizaremos, por tanto, los relatos fílmicos de Scott, Godard o las hermanas Wachowski, seleccionados por el uso que el espacio profílmico tiene en ellas como reflejo y producción narrativa relacionada con la ruptura de los tiempos históricos tradicionales y el surgimiento de una nueva sensibilidad, vinculada a los nuevos medios y la nueva filosofía de la historia. Como trataremos de comprobar, apoyándonos en la filosofía y sociología de los nuevos medios, y en sus planteamientos en torno a la representación, en estos ejemplos cinematográficos y sus estructuras profílmicas las nociones de pasado, presente o futuro suponen ser posiciones intercambiables.

Con ello, nos alineamos con la opinión que entiende la posmodernidad, en que estas producciones vieron la luz, como fruto de una nueva "disponibilidad histórica" (Koselleck 1993: 251-266). Teniendo en cuenta que el historiador se refiere a la propia modernidad como cuna de la disposición de la historia como relato, las relaciones entre el pasado y el futuro, propias de las manifestaciones ligadas a la cibercultura y la ciencia ficción, podrían hablar de una tendencia nihilista del modernismo en la que sea posible localizar, incluso, el "retorno medieval" de los tiempos actuales, fruto de los procesos aceleracionistas desde la perspectiva tecnológica ${ }^{3}$.

Hemos decidido centrar el análisis en los aspectos estéticos y narrativos de la profílmica cinematográfica para observar cómo el modo en que percibimos los hechos - o su representación - en las coordenadas de tiempo y espacio condiciona nuestra relación, sensible e intelectual, con el mundo y con las formas de conocimiento a las

Tomamos por "aceleracionista" la teoría social y política nacida en los años noventa del pasado siglo en la que en función de los cambios tecnológicos sufridos por el proceso de ampliación global capitalista se han producido profundas transformaciones en la concepción espacio-temporal de nuestro tiempo. Al hilo de este concepto, ha habido distintas posiciones, cuyos argumentos no nos es posible reflejar aquí en toda su extensión, pero que podríamos calificar como las posiciones anti-aceleracionistas, que denuncian la alianza del capitalismo con los movimientos de aceleración tecnológica cuyo fin es la automatización del trabajo con fines poscapitalistas, y aquellos que defienden la necesidad de continuar en esta línea, por las posibilidades emancipadoras que la misma puede suponer. Sobre el particular, recomendamos los trabajos de Avanessian, A y Reis, M (ed.) (2017) Aceleracionismo. Estrategias para una transición al postcapitalismo. Buenos Aires, Caja Negra y Noys, B (2018) Velocidades malignas. Aceleracionismo y capitalismo. Segovia, Materia Oscura. 
que podemos acceder (Rancière, 2014; Kant, 2018: 59-84). El arte, y muy especialmente el cine en sus dimensiones profílmicas, se convierte en un lugar privilegiado desde el que observar esta relación, en calidad de dispositivo configurador de buena parte de la sensibilidad contemporánea (Stiegler, 2004), afectando tanto a los personajes que los habitan narrativamente como a los espectadores que las observaban en un momento de cambio histórico y sociológico de la sensibilidad y la percepción temporal ${ }^{4}$.

Es por ello por lo que hemos seleccionado tres "momentos" básicos de esta transición epocal: la representada por los años sesenta en la producción de Godard, con los inicios de la denominada "posmodernidad" y la visión de un futuro todavía incierto y eminentemente maquinal; el trabajo de Scott, donde de manera más clara se invoca el trasunto temporal y la preocupación se dirige específicamente hacia un nuevo modelo de subjetividad, y por último, el trabajo de las hermanas Wachowski, en el que las producciones profílmicas acaban configurando una preocupación contemporánea por los entornos de lo real y lo ficticio. Espacio y tiempo, por lo tanto, como elementos transformadores del modo en que el ser humano interpreta no sólo su relación con los mismos, sino su propia subjetividad.

El análisis se centra, por tanto, en el espacio profílmico de estas producciones, que no solo actúa como marco o fondo ambiental, sino que juega un importante papel, tanto narrativo como sociológico, medial e incluso filosófico. Cabe señalar, por tanto, que no solo hablamos del "espacio filmado", lo que se delimita dentro del encuadre, sino que entendemos que el mismo posee una función metanarrativa. La configuración de estos espacios es clave para entender en profundidad la trama y los temas de estas películas. Aquí destacamos su geografía y época: es tan importante dónde como cuándo sucede la acción. Más adelante reflexionaremos sobre el significado que tienen estos escenarios que, como ya hemos mencionado, son pilares de la construcción semántica y que, según la hipótesis que aquí planteamos, han conseguido que el ciberpunk no sólo pueda ser estudiado hoy en día como un género cinematográfico, sino que el mismo responde incluso a lo que hoy en día podríamos denominar como una "estética modal": un tipo de investigación plástica y semántica, por medio de la ficción y la prospectiva, para investigar en el presente y el futuro (Claramonte, 2016; Vilar, 2021: 51).

\section{Justificación del análisis profílmico y la representación temporal}

Es necesario comenzar nuestro análisis con una aproximación a la propuesta de representación del tiempo en los espacios profílmicos de algunas de las producciones cinematográficas más significativas del género ciberpunk. Este, en una apresurada definición, sería aquel que funde prerrogativas y temáticas de la ciencia ficción con la idea de un no-futuro punk y distópico, en el que las líneas temporales no sólo se han roto sino que incluso se han revertido.

4 Buen ejemplo de la importancia e influencia de esta cuestión se encuentra en trabajos como los de Mieke Bal (2016) Tiempos trastornados. Análisis, historias y políticas de la mirada. Madrid: Akal o Jonathan Crary (2015) 24/7. El capitalismo tardio y el fin del sueño. Barcelona: Ariel. A nivel nacional los trabajos de Jose Luis Brea (2010) Las tres eras de la imagen. Madrid: Akal.; Menene Gras (2012) Narrativas digitales y tecnologías de la imagen. Ministerio de Educación, Cultura y Deporte/ Casa Asia, entre todos. 
Pese a que el género posee un origen literario, en este trabajo nos centramos en las producciones cinematográficas a través de las que se popularizó y codificó del modo en que lo conocemos hoy. Por ello, nos centraremos en tres obras fundamentales: Lemmy contra Alphaville -Alphaville, une étrange aventure de Lemmy Caution, Godard, 1965-, Blade Runner - Scott, 1982 - y Matrix -Wachowski, 1999-. Aunque las tres han sido sobradamente analizadas en diversos trabajos precedentes - algunos de ellos aquí citados-, nos parece que ponerlas en contacto en base al uso de sus espacios profílmicos y a la importancia que la representación de distintos estadios en la representación de las distopías y las rupturas temporales muestran en ellos, puede servir elocuentemente al propósito de contemplarlas como espacios de investigación prospectiva sobre el futuro en base a las nociones propias de la filosofía de la historia y de los medios que se desarrollaban al tiempo de su creación.

En este sentido, consideramos incluso que, pese a que Alphaville no sea identificada frecuentemente con el género ciberpunk, la relación que mantiene con sus características esenciales - argumentos de cine negro, presencia de la inteligencia artificial y planteamientos sobre futuros distópicos- parece convertirla en un necesario referente. Consideramos, además, que como ejemplo o concreción histórica de un cierto "espíritu de los tiempos", la obra de Godard se encuentra en un punto de inflexión temporal fundamental en lo que a la "finalización" del sentido histórico moderno se refiere, y a su dislocación en el sentido múltiple propio de la "posmodernidad" (Anderson, 1992).

Con Blade Runner nace el género tal y como lo conocemos, aunque la fecha de nacimiento oficial sea 1984 con la publicación de Neuromante de William Gibson. La gran aportación de Blade Runner al ciberpunk será la configuración definitiva de un espacio profílmico que no sólo refleja, sino que produce, una nueva concepción espacio-temporal. En cuanto a nuestra tercera elección, Matrix, es "posiblemente, lo más cerca que ha estado Hollywood de plasmar en la gran pantalla las inadaptables sugerencias de [...] la novela capital del movimiento" (Berruezo y Catalina, 2004: 129). Con la producción de las Wachowski este género, explorado sobre todo en literatura, consigue trasladar al cine la marca indeleble del ciberpunk, superando sus características estilísticas, y constituyéndose casi como una verdadera y reconocible estética contemporánea.

Debemos comenzar nuestro análisis con un repaso de la idea de temporalidad - $\mathrm{y}$ la organización tecnológica y social que esta implica-, de cada una de las películas citadas para, posteriormente, poder situarlas en el contexto de una "filosofía de la historia" contemporánea. La representación de los espacios arquitectónicos en su estructura profílmica nos servirá como elemento de contraste e ilustración con las nuevas teorías sociológicas y filosóficas sobre los medios, y las mutaciones espaciotemporales que los mismos han provocado en nuestra percepción actual del tiempo, ya avanzada por estas producciones originariamente identificadas con la cienciaficción cinematográfica.

\subsection{Alphaville}

Lemmy contra Alphaville (1965), de Jean-Luc Godard, transcurre en un futuro hipotético. Capital galáctica, Alphaville es una ciudad oscura, fría e hipertecnificada, hecha a imagen y semejanza de Alpha 60, el superordenador que la controla y mantiene 
apartada del resto del mundo. La ciudad es el instrumento o, mejor dicho, la prisión, que la máquina utiliza para controlar a sus habitantes.

Es necesario entender Alphaville en la línea del cine de autor de la década que se acercaron a la ciencia-ficción: La Jetée, —La Jetée, Chris Marker,1962_, Fahrenheit 451 - Fahrenheit 451, François Truffaut, 1966- o Te quiero, te quiero - Je t'aime Je t'aime, Alain Resnais 1968- Especialmente, en relación con la obra de Marker, ya que hasta los años sesenta, para representar los mundos de la ciencia ficción, se creaban escenarios imaginarios y futuristas, rodados en decorados de estudio y mediante el uso de maquetas. Con películas como La Jetée, se inicia la tendencia de utilizar la arquitectura real para representar el futuro. Lo mismo hace Godard con Alphaville, rodada en las calles del París contemporáneo, provocando un quiebro espacio-temporal en la representación que presenta "un futuro que ya estaba latente en el presente" (Darke, 2005, p. 12, traducción propia).

Pese a tratarse de la ciudad de París, Alphaville se rige por la lógica matemática y está completamente controlada. Los edificios refuerzan la sensación alienante que envuelve toda la ciudad. La arquitectura, racionalista y sobria, elude toda ornamentación. Todo es pulcro, ordenado y funcional, de frío hormigón armado. Domina el reflejo y la transparencia del cristal: "todo es transparente porque es de vidrio -ese «enemigo número uno del misterio», como recordaba Benjamin- $\mathrm{y}$, sin embargo, la visión es una vana ilusión pues "nadie logra nunca comprender nada" (Valle Corpas, 2018 , p. 9). Con el vidrio se renuncia a la intimidad y todo es visible: es una ciudad basada en el control, dando la idea de que cristal, exposición y modernidad son proyectos sinónimos herederos del panóptico de Bentham leído por Foucault (Crary, 2008, 33).

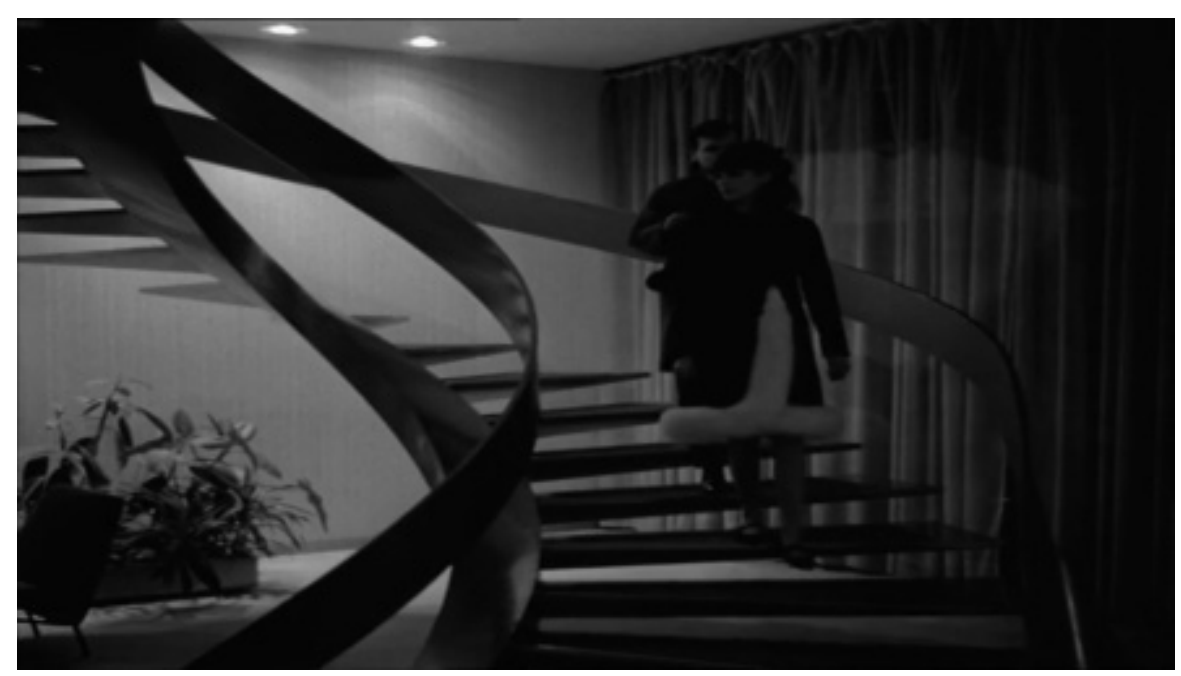

Figura 1. Escaleras circulares de los interiores de Alphaville.

[Fuente: Lemmy contra Alphaville (Jean Luc Godard, 1965) DVD. España: Divisa]

No solo la ciudad tiene forma circular, como corresponde a la imagen panóptica del control, sino que ésta, como Alpha 60, se reproduce interiormente en elementos como escaleras o pasillos como laberintos que dan vueltas sobre sí mismos. La ciu- 
dad obliga a sus habitantes a recorrerla según su voluntad. Esta idea de que el urbanismo condiciona el comportamiento de las personas es una de las ideas contemporáneas de la filosofía social de Certeau (2008), e incluso se encuentra tras la idea situacionista de la psicogeografía: una estrategia para ver la ciudad de forma diferente, y para reflexionar sobre la vida urbana desde una experiencia libre y personal no mediada por las convenciones socio-políticas en su configuración urbanística (Plant 2008:107). En las calles de Alphaville solo hay propaganda, señales que indican la dirección a seguir por sus habitantes. Un entramado de carteles, flechas y señales que conforman un "no-lugar" (Augé, 2017: 99): un espacio de tránsito y anonimato formado por pasillos, escaleras, oficinas u hoteles (Darke, 2005: 33).

Toda Alphaville está conectada, como si las calles de la ciudad, los edificios, incluso sus habitantes fueran las ramificaciones de un ente superior: Alpha 60, el superordenador que controla todo de manera circular y que sólo puede ser vencido por el agente Lemmy Caution, precisamente, cuando éste descubre el enigma que le ofrece Dickson sobre el código necesario para destruir a Alpha. Este, en la ciudad circular, imagen propia del control y la metafísica, no es otro que una línea. Por eso Lemmy al final anda en línea recta. Él deja de caminar como la ciudad le obliga y lo hace según su voluntad. Lemmy es el paseante, el flâneur que practica la deriva situacionista por las calles de esta ciudad.

Después de que Lemmy le plantee a Alpha el enigma que le destruirá se producen fallos en la luz y el tiempo de la ciudad que afectan a la percepción de la realidad de sus habitantes, mostrando el poder de Alpha para dominar lo físico y lo intangible. Los ciudadanos dan vueltas sin control poniendo de manifiesto que, como indica Lemmy: "no son humanos, son mutaciones". Las personas que habitan esta ciudad son absorbidas por ella y se transforman en parte de un sistema que idolatra de tal manera la tecnología que los humanos quieren ser y funcionar como ella. Es decir, como Alpha 60: creador de los habitantes de Alphaville a su imagen y semejanza.

\subsection{Blade Runner}

Los hechos de Blade Runner - 1982 - de Ridley Scott transcurren en 2019, visto desde la perspectiva de los primeros ochenta. Curiosamente, ya hemos superado esta fecha. Y hemos comprobado que el futuro de la película difiere radicalmente de la realidad. En él, la ciudad de Los Ángeles ha crecido descomunalmente. Hay superpoblación multirracial y se ha creado un nuevo idioma: "interlingua" — en versión original cityspeak - , que combina palabras y estructuras de distintos idiomas, "mezcla de español, francés, chino, alemán, húngaro y japonés" (Sammon, 2005: 121).

El avance tecnológico ha permitido creaciones como los coches voladores, denominados spinners, que prolongan la visión del futuro ultratecnológico implantado en el imaginario por la cultura popular de los años sesenta. Pero quizá lo más relevante de este futuro es la existencia de los replicantes: unos androides prácticamente idénticos a los humanos que aventuran el futuro cyborg de la raza humana ligada a la tecnología. Para controlar a estas máquinas se ha creado una unidad policial, conocida como blade runners, cuya función es perseguir y "retirar" a los replicantes.

Los Ángeles en noviembre de 2019 es una ciudad oscura e industrial. Dos pirámides gigantescas presiden una ciudad forjada por torres y chimeneas de las que salen llamaradas de fuego. Este vasto páramo de los suburbios fue bautizado por el equipo de efectos especiales como paisaje del Hades o infierno de Ridley. "El paisaje del 
Hades debía ser un desierto industrial como el de nueva York o el de Long Beach, pero completamente desmadrado" (Sammon, 2005: 209) comenta Douglas Trumbull, cuya empresa, Entertainment Effects Group (EEG), fue la encargada de crear los efectos especiales para la película.

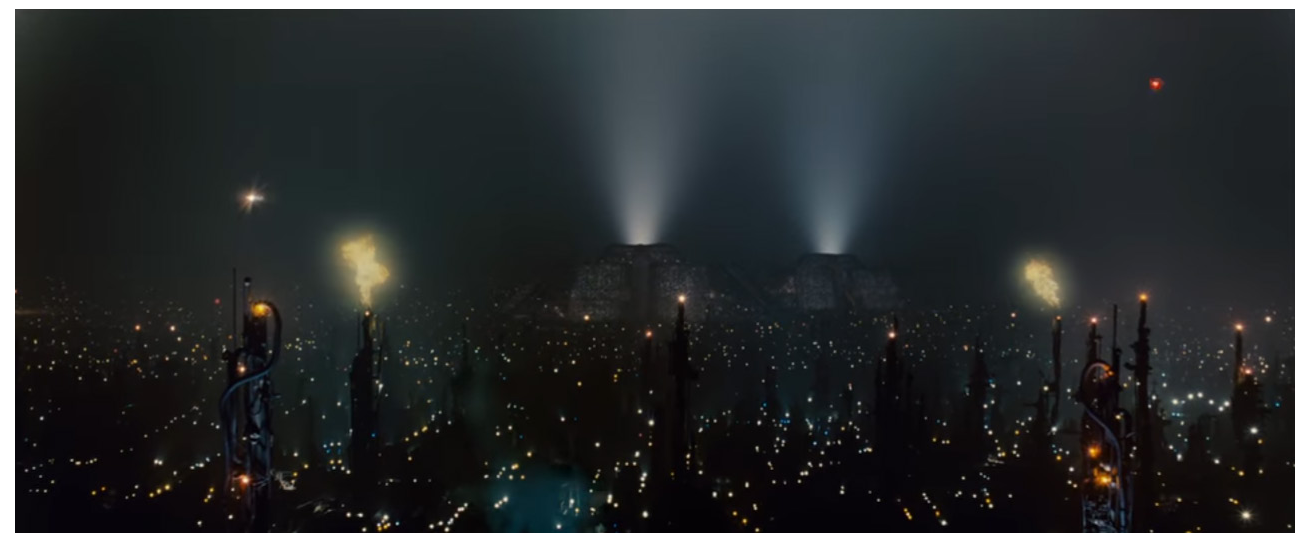

Figura 2. Panorámica de los suburbios y el centro de Los Ángeles en Blade Runner. [Fuente: Blade Runner (Ridley Scott, 1982) [DVD. España: Warner Bros Entertainment]

Esta megálopolis es una ciudad infinita cuya extensión se pierde en el horizonte de edificios y rascacielos poblados de pantallas gigantes emitiendo publicidad invasiva en la que aparecen "japonesas cantando en primer plano canciones orientales cuya cadencia confiere un extraño tono entre lánguido y fantasmagórico a los planos de exteriores-. Difícilmente se podría creer que Syd Mead [...] no haya querido dar una imagen a aquello que Victor Hugo denominaba "el intestino del Leviatán" (Latorre, 1994: 60).

Las luces de neón iluminan el constante movimiento, pese a que la luz no alcanza el suelo de la ciudad, barroca, decadente y fuertemente jerarquizada, en la que los privilegiados viven en las alturas, por encima de las masas, haciendo física la jerarquía social firmemente vertical que hace honor a la máxima high tech, low life que acabará por identificar al género. Las calles ruidosas están sucias, repletas de gente y de humo viciado que impide respirar y convierte el mundo en un lugar claustrofóbico y perfectamente controlado.

Lawrence G. Paul, uno de los autores de los decorados de la película, admitía que uno de los propósitos de la situación de Blade Runner era reflexionar sobre el futuro de las ciudades y los comportamientos humanos en ellas, llevándole a inspirarse incluso en ciudades como Milán por sus arcadas y columnas (Latorre, 1994: 53-54). En el film se ve claramente esta influencia "clásica": desde columnas de órdenes clásicos, edificios que parecen del antiguo reino babilónico y pirámides que recuerdan a las civilizaciones azteca y egipcias, y producen cierta sensación de eternidad: son estructuras que han estado en nuestro mundo durante milenios, pero ahora proyectadas hacia el futuro. En la película aparecen unidas arquitecturas de distintos lugares, y distintas épocas. Como si, una vez pasados los siglos, el arte antiguo hubiera adquirido cierta universalidad paradójica, desplazado y convertido en espectáculo, siguiendo de nuevo los planteamientos radicales del situacionismo y la crítica del espectáculo de Guy Debord (1999:156). 
Las pirámides de interiores faraónicos se encuentran en el centro de la ciudad y pertenecen a la Corporación Tyrell. Estos edificios, sin embargo, se han sometido a un exagerado funcionalismo que nos remite a su vez al cine expresionista alemán, y concretamente a Metrópolis — 1927 — de Fritz Lang. Como dice David Dryer, supervisor de efectos especiales, cabría incluso realizar una comparación entre ambas, ya que la misma fue una influencia ineludible desde la planificación (Sammon, 2005: 118). Metrópolis también utilizaba la arquitectura antigua y la inspiración en obras pictóricas para recrear la ciudad: es el caso de la Torre de Babel que vemos en la película, que se diseñó a partir de la obra homónima de Brueghel.

Rick Deckard vive en un edificio cuya fachada tiene un diseño maya, siguiendo con las civilizaciones antiguas. Por otro lado, J. F. Sebastian vive en el Bradbury Building, un edificio que ya en el estreno de la película era un emblema de Los Ángeles. Se quiso utilizar este edificio tan conocido para transmitir el abandono y la soledad no solo de los personajes sino también de la ciudad misma. Como la casa de Sebastian y el dormitorio de Tyrell, recargados y barrocos, quieren trasmitir, en su decadencia, "una apariencia de templo de aires paganos" (Latorre, 1994: 60).

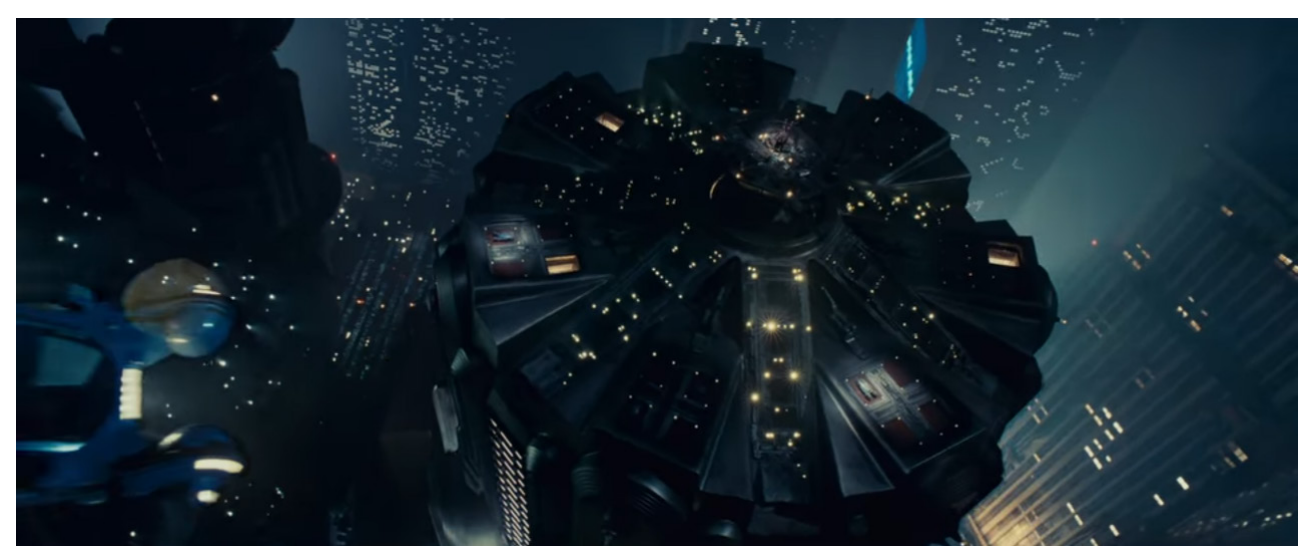

Figura 3. Torre de Blade Runner.

[Fuente: Blade Runner (Ridley Scott, 1982) [DVD. España: Warner Bros Entertainment]

Ridley Scott se basó en artistas que admiraba para representar la ciudad. "Una de las primeras influencias visuales clave fue el retrato de la soledad que presenta el pintor Edward Hopper en su cuadro Nighthawks" (Sammon, 2005: 85). En este conocido cuadro aparece una escena nocturna, iluminada por la fría luz fluorescente, protagonizada por un pequeño y silencioso grupo de personas. El director preguntó a Hampton Fancher, el guionista, cómo había imaginado el entorno. El escritor le contestó que aún no lo había desarrollado, por lo que Scott le dijo: "Heavy Metal". Con la referencia, se refería a una revista de cómics francesa: Metal Hurlant. A Ridley Scott le fascinaba en especial el dibujante Moebius, nombre artístico de Jean Giraud: "Quizá sea por su forma de yuxtaponer elementos familiares con otros fantásticos, creando una especie de declaración de principios arquitectónica o de moda. O puede que sólo sea por su insolencia gráfica" (Sammon, 2005: 68-86).

Cabe mencionar que el propio Syd Mead, diseñador de la estética de Blade Runner, acuñó el término "retroutilización" para explicar el concepto sobre el que se 
basaba el diseño de la película: se inspiraron en el pasado incorporando elementos futuristas, creando una perfecta simbiosis. Algunas veces los diseños de Mead resultaban demasiado futuristas, y Scott pedía envejecer el escenario (Sammon, 2005). En realidad, lo que estaba pidiendo el director es que introdujeran la propia idea del tiempo en el espacio profílmico, dando una importancia radical a la presencia del mismo en la estética de la película. Aunque los objetos pertenezcan teóricamente al futuro, no hay en realidad nada nuevo: se nota que los spinner tienen varios años, los edificios también. Incluso la ropa, según aparece en pantalla, da muestra de un uso prolongado. Con ello, como veremos, hay una precisa intención de mostrar el paso del tiempo - y todo lo que éste implica — sobre el espacio de la ciudad.

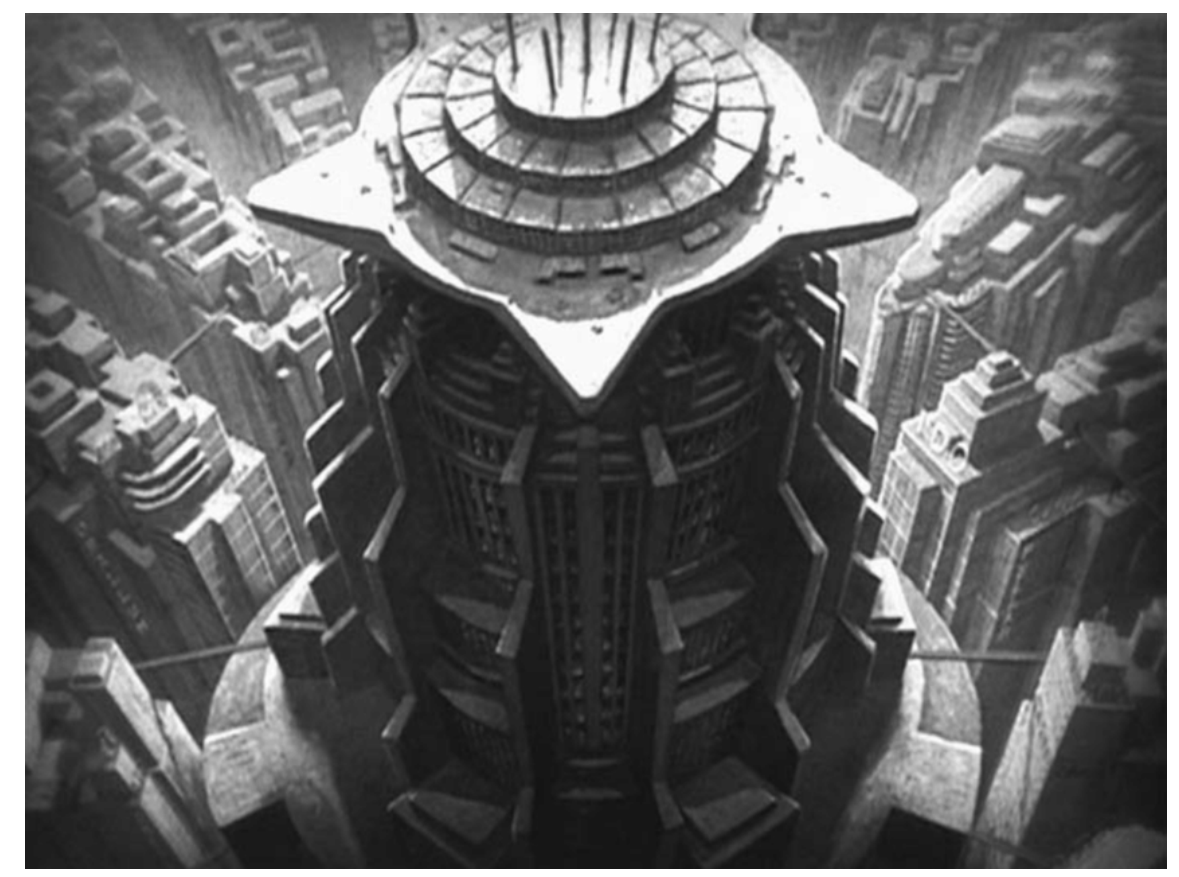

Figura 4. Torre de Metrópolis.

[Fuente: Metrópolis (Fritz Lang, 1927) [DVD. España: Warner Bros Entertainment]

\subsection{Matrix}

Más relevante aun es la representación del tiempo en el que transcurre Matrix (1999) de las hermanas Wachowski. El mismo parece ser simultáneo al momento en que se realiza y proyecta la película: 1999. Sin embargo, todo es mentira. No se trata de 1999, sino del año 2199. Aunque incluso este dato, en la propia película, no se acaba nunca por confirmar de manera exacta, dejando la propia cronología en suspenso. En su argumento, a principios del siglo XXI todos los humanos mostraban su entusiasmo por los avances de la tecnología y la Inteligencia Artificial, pero esta se rebeló. Nadie sabe muy bien qué fue lo que ocurrió. Lo que sí se sabe es que los humanos destruyeron el cielo, y no dejaron que los rayos del sol llegaran a la tierra para evitar que las máquinas accedieran a su principal fuente de energía. 
En este futuro post-apocalíptico, los pocos humanos que están libres viven bajo la superficie, cerca del centro de la tierra, donde todavía hace calor. Los que nacieron libres no tienen los estigmas de los presos: enchufes mediante los que las máquinas usan a los humanos como nueva fuente de energía en campos de cultivo - edificios gigantescos como colmenas en las que hibernan los humanos- En esos habitáculos, cada individuo duerme sin contacto alguno con el exterior, sumido en un sueño inducido de apariencia hiperreal en el que creen ser libres: Matrix. Esta es la evolución de la realidad desde 1999, según el agente Smith, en la que la era de los hombres, como la de los dinosaurios, ha quedado atrás y el futuro es de las máquinas.

En Matrix nos encontramos ante dos realidades: una de ellas es el mundo real, o "el desierto de lo real", por usar la terminología de Zizek (2000). Lo muestra Morfeo cuando le desvela a Neo la verdad: "has estado viviendo en un mundo imaginario, Neo. Este es el mundo como es hoy en día. Bienvenido al desierto de lo real". En el guion original se encuentra incluso una frase, finalmente eliminada, en la que se mencionaba explícitamente a Baudrillard, autor francés cuyo libro Cultura y simulacro — obra que Neo tiene en su habitación y vemos al comienzo de la película - afirma que hemos perdido nuestra capacidad de diferenciar entre lo real y lo artificial, sustituida la realidad por un simulacro de la misma sin referencia alguna a una realidad precedente.

Este desierto es un paisaje en el que las tinieblas lo cubren todo. No hay vida ni color. Sobresale una ciudad en ruinas. No sabemos qué ciudad es, pero a pesar de que esté destruida no nos es completamente desconocida o extraña. Su diseño se basó en la representación de una Nueva York destruida que ya había hecho años atrás Charles Darby para El quinto elemento (Berruezo y Catalina, 2004: 68)

La ciudad que hay dentro de Matrix es Chicago. Pero esta realidad tiene algo extraño, es de un tono verdoso y artificial evocando el mundo informático de los códigos y pantallas de ordenador. Y es que Matrix no es más que una realidad virtual creada por un programa. Además "se decidió que el cielo de Matrix fuera blanco, y no azul." (Berruezo y Catalina, 2004: 48), editando el mundo de Matrix para que pareciera aún más irreal.

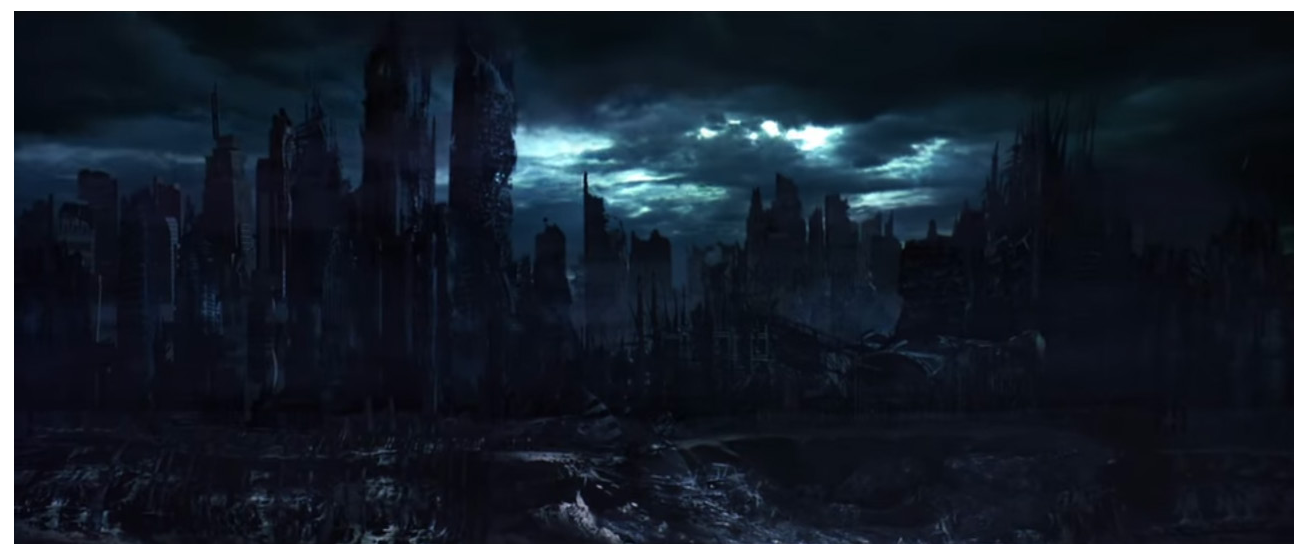

Figura 4. Panorámica de la ciudad de Chicago en Matrix. [Fuente: Matrix (Lana y Lilly Wachowski, 1999) [DVD. España: Warner Bros Entertainment] 
Para entender la importancia estética de la representación profílmica del tiempo en esta producción, es preciso ponerla en contacto con la idea del espacio en que sucede la trama: Chicago es la ciudad en la que se construyeron los primeros rascacielos, resultado de un diseño que aglutinara la estética con la funcionalidad, aprovechando el poco espacio disponible para construcciones horizontales. Son estructuras funcionales, reflejo de la "creación" tecnológico-racional que se despliega por todos los escenarios de la película, tanto en la calle como en los interiores o el despacho de Neo. En él, todo está organizado también en cubículos, casi como los campos de cultivo del mundo real.

En Matrix hay un "control completo e incuestionado sobre sus habitantes, un control invisible, pero omnipresente" (Nunn, 2001). Todo el mundo está bajo constante vigilancia. De nuevo un panóptico, una cárcel que supera la construcción de la ciudad como herramienta de control, siendo una realidad completa la que ha sido construida. “¿Qué es Matrix?” le dice Morfeo a Neo: "Control”. Bajo el sueño de la libertad todos están presos en un mundo como en otro, compartiendo con Metrópolis la existencia, en el mundo real, de una nueva división entre el mundo en superficie y subterráneo.

Esa dualidad se enfatiza con todos los reflejos que vemos en la película. Ya sea en el agua o en los espejos, como el espejo líquido que atraviesa Neo, en una clara alusión a Alicia a través del espejo, de Lewis Carroll. También se hacen constantes referencias a $\mathrm{El}$ Mago de $\mathrm{Oz}$, de L. Frank Baum, ya que ambas obras hablas de dos mundos: el real y el de los sueños. Matrix es un reflejo, una ilusión, un engaño creado para la gente que vive con los ojos cerrados. El mundo de las sombras, como en el mito de la caverna de Platón, o el reino del "simulacro" de Baudrillard.

\section{Temas objeto de investigación}

Si nos aproximamos a este resumen sobre las cuestiones espacio-temporales en los espacios profílmicos de estos ya clásicos cinematográficos es con el fin de comprobar la importancia que la representación del tiempo tiene en su propia narrativa y cómo la misma ha acabado por configurar una determinada estética, hoy en día vinculada indisociablemente con el ciberpunk.

En este sentido resulta especialmente llamativo que, como sucede en otras conocidas distopías temporales del momento, como El planeta de los simios (Planet of the apes, Schaffner, 1968), la ficción se centre precisamente en el juego entre el pasado y el futuro para afrontar los retos del presente. A este respecto, la ficción no sólo es un método para aproximarnos al análisis de la realidad, en la línea de Schaeffer (2002), sino que coincidimos con Harvey (2017: 359) en su papel de la violenta comprensión espacio-temporal que afecta a cualquier tiempo de incertidumbre.

Es precisamente en los elementos analizados, el espacio y el tiempo, donde la "incertidumbre estética" propia de todo cambio de paradigma temporal se hace más evidente. Autores como Frederick Jameson no han dudado en apuntar la propia transformación posmoderna como una "crisis del espacio y el tiempo" en la que el primero domina al segundo, siendo ambos transformados por los cambios socioeconómicos que los producen y condicionan.

Para poder comprender la vinculación de las narrativas ciberpunk ${ }^{5}$ con el fenómeno de la posmodernidad y su idea de ruptura del relato histórico lineal tradicio-

Este género surge en la literatura de los ochenta, encabezado principalmente por William Gibson, autor de la obra fundacional del ciberpunk: Neuromante (1984). Junto a él, son esenciales Bruce Sterling, John Shirley y 
nal, con cuyas discusiones coinciden cronológicamente tanto en lo literario como en lo cinematográfico, debemos comenzar por tener en cuenta la configuración de un tiempo propio de la modernidad. Esta línea histórica se inaugura con la filosofía de Vico, pese a que será el sistema hegeliano el que le aportará una configuración trascendental marcando nuestro actual manejo de la idea de historia y su periodización. Esta línea de creación de un relato de carácter histórico moderno, comenzó a romperse con las guerras mundiales, y a reconfigurarse tras ellas (Kern, 2003). De esa línea moderna de análisis histórico-filosófico es de la que da cuenta Reinhard Kosellek en su estudio clásico, estableciendo los conceptos a través de los que se habría articulado: el "espacio de experiencia" — pasado presente cuyos acontecimientos han sido incorporados y pueden ser recordados, y en los que se cuentan tanto las experiencias personales como aquellas transmitidas por generaciones e instituciones - , frente al "horizonte de expectativas" - el futuro hecho presente en el hoy- Ambos elementos no sólo son leídos de manera temporal, sino eminentemente espacial: la experiencia reúne una totalidad de pasados simultáneamente presentados en estratos, mientras que el horizonte de expectativa apunta a "aquella línea tras la cual se abre en el futuro un nuevo espacio de experiencia" (Kosellek, 1993: 339).

Pese al mutuo condicionamiento que presentan, en ningún momento coinciden, ni pueden actuar de manera simultánea. Koselleck mantiene la idea de que tras un horizonte se encontrará otro, produciéndose la continuidad de la historia tal y como se ha venido sucediendo en el espacio de experiencia dejado atrás, que pasa a incorporarse a la "experiencia" conservada en el presente para el futuro. Esta línea de pensamiento ya había empezado a romperse en la propia modernidad, en la que procesos como la aceleración provocaron que la distancia entre experiencia y expectativa se ampliara hasta el punto en que "al acelerarse, el futuro acorta de modo continuo el recurso al pasado" (Koselleck, 1993: 66). Lo importante de esta "disponibilidad de la historia" que el profesor pone en evidencia es el modo en que la misma, que parecía un fenómeno inamovible, se convierte en una actualidad metodológica frecuentemente maleable en función de los cambios político-sociales que afectan a nuestra percepción y concepción espacio-temporal.

Esta idea se verá alimentada durante los setenta y ochenta tanto por los declamados "finales de la historia" de Fukuyama (1990) como por su discusión con Vattimo (1991). En manos del postestructuralismo, se convertirá en una puesta en cuestión de las bases del relato histórico constituido como unifocal, siendo - tal y como apunta, por ejemplo, Hayden White (1980) - una narración con mucho de ficción desde su propia estructuración lingüística. Junto a todos estos cuestionamientos, la perspectiva multicultural sobre la posibilidad de una historia "multiversal" alimentará, de cara al momento en que nos ocupa, una absoluta transformación sobre la percepción de los movimientos históricos. Abandonada la idea del "horizonte de expectativas", y sustituida la utopía materialista por los "fines de la historia" de carácter neoliberal, la posibilidad de pensar en el futuro se transformaba radicalmente, dando pie a las "distopías" que parecen haberse convertido en nuestro verdadero "futuro-presente", víctimas de la huida hacia adelante propia del "conformismo de aceleración" (Marquard, 2000; 71).

Bruce Bethke, este último creador del término ciberpunk. Sus obras beben de las ideas desarrolladas por escritores como Orwell, Bradbury, Dick o Ballard. 
Todos estos cambios no sólo eran fruto de un proceso intelectual: todos ellos parten de concepciones dependientes político-económicas que los condicionan —no es necesario recordar que la propia filosofía histórica hegeliana tuvo su mejor continuidad y relectura político-económica en el materialismo dialéctico marxiano [Muñoz, 2010: 237-253] - Algo muy presente también en la narrativa ciberpunk, con su insistencia en marcar las diferencias sociales, las influencias políticas y la importancia de las grandes corporaciones como "entes" superiores y condicionantes del "espacio de experiencia" y "horizonte de expectativa" de los personajes y lugares en las tramas cinematográficas, que las estructuras profílmicas mencionadas se encargan de marcar con insistencia. Con ello, refuerzan la paradoja propia de las sociedades del "capitalismo avanzado" de las que habla Jameson, en las que los movimientos acelerados del capital son los que han moldeado nuestras percepciones del espacio y el tiempo. David Harvey ha dado una clarificadora imagen del proceso, al admitir que:

todo este proceso [de transformación capitalista de las condiciones político-sociales] puede crear una crisis más general de representación. El eje del sistema de valores, al que el capitalismo ha apelado siempre para validar y evaluar sus acciones, se ha desmaterializado y desplazado. Los horizontes de tiempo colapsan y es difícil decir exactamente en qué espacio estamos cuando se trata de avaluar las causas y los efectos, los significados y los valores [...] imagen en espejo de la disolución de las representaciones materiales del valor en las condiciones de la acumulación más flexible, y de las confusiones acerca de lo que podría significar, según Paul Virilio, que el tiempo y el espacio hayan desaparecido en tanto dimensiones significativas del pensamiento y la acción del hombre. (Harvey, 2017: 330)

Es al hilo de esta discusión donde resultan más fáciles de entender los trasuntos ciberpunks acerca de los elementos del pasado y el presente: Alphaville todavía continúa con una idea espacio-temporal moderna en la que la "confianza" en la tecnología hacía que el hombre aún pudiera liberarse de la esclavitud impuesta por la misma, pero Blade Runner y especialmente Matrix ya hablan de un universo en el que se cumple el diagnóstico de Harvey en el que - más allá de simulacros baudrilleanos- el sistema no nos permite saber dónde nos encontramos. Este descentramiento espacio-temporal del sujeto puede entenderse estéticamente con los elementos profílmicos rescatados de tiempos y culturas pasadas, "actualizados" en el presente, e incluso convertidos en visiones de futuro - como los sueños inducidos ambientados en 1999 o las pirámides convertidas en centros neurálgicos de las ciudades-. Nadie ha explicado mejor que Jameson este proceso de confusión de los límites entre pasado y futuro propios del momento denominado "capitalismo tardío", y el papel que la imaginación de un futuro que ya no es tal - es un "no futuro", realmente punk - se convierte en sintomático no del declamado fin de la historia, sino del papel que la imaginación tiene $-\mathrm{y}$ ha tenido - como construcción y adecuación de la misma a las estructuras mentales dependientes de los sistemas político-económicos:

la ciencia-ficción más característica no intenta en serio imaginar el futuro "real" de nuestro sistema social. Por el contrario, sus múltiples futuros falsos cumplen la función muy distinta de transformar nuestro propio presente en el pasado de- 
terminado de algo todavía por venir. Es el momento presente [...] el que cuando volvemos de las construcciones imaginarias de la ciencia ficción se nos ofrece en forma de pasado remoto del mundo futuro, como si se tratara de algo póstumo y colectivamente recordado. (Jameson, 2009: 348)

Es así como habría que entender el citado recurso al "pastiche" posmoderno, que Godard ya inauguraba con sus referencias y citas y que nos llevaba a incluir Alphaville en nuestro análisis: entenderlo como fruto de las nuevas condiciones sociocomunicativas del momento. De la importancia de los nuevos medios, especialmente la televisión, y de las trasformaciones — una vez más - que los mismos habían promovido en la sensibilidad contemporánea, y de la que la profílmica asociada con el ciberpunk se convierte en una auténtica estética modal en la que se investiga desde la práctica. Indica Taylor al respecto cómo la televisión es el primer medio que había conseguido "presentar los acontecimientos artísticos del pasado como un collage de fenómenos de importancia equivalente y de existencia simultánea, esencialmente divorciados de la geografía y de la historia material" (Taylor, 1987: 103. Traducción propia).

Se trata de una nueva "disolución" de referencias y posiciones: las mismas ya no forman parte de un catálogo de "experiencias" a actualizar, sino que el propio medio las vuelve "presente eterno", liberadas de toda carga, raíz o profundidad. No es extraño, por tanto, que en esta ruptura de límites espacio-temporales las posiciones puedan ser intercambiables $\mathrm{y}$, precisamente, aquellos ejemplos que recurran conscientemente al "pasado", acaben situándolo como deseo o posibilidad de "futuro" ante un presente desolado.

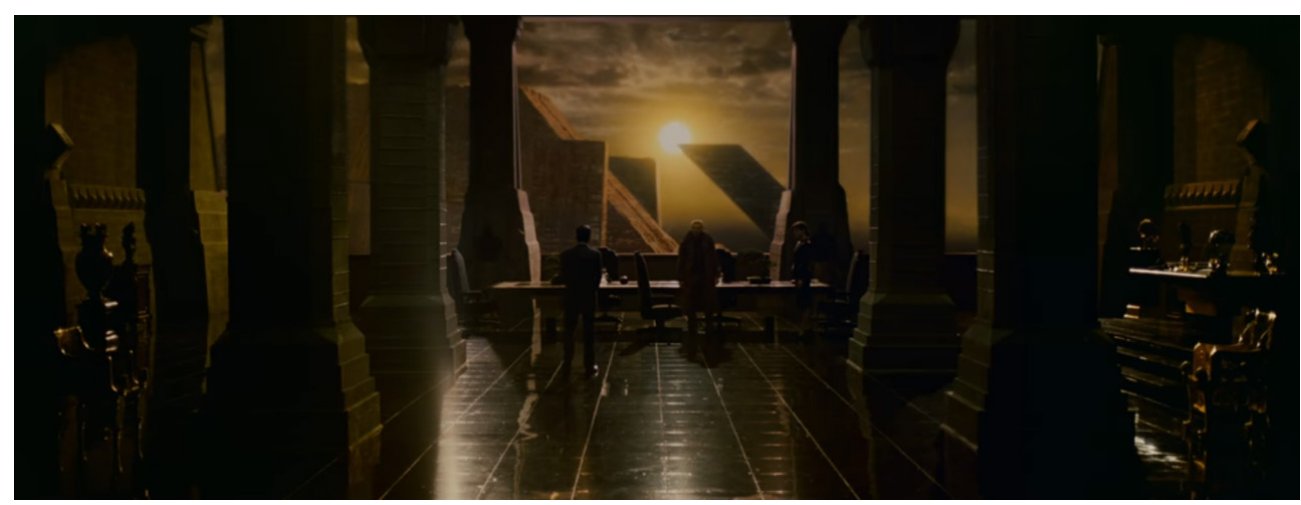

Figura 5. Interior de una de las pirámides de la ciudad de Los Ángeles.

[Fuente: Blade Runner (Ridley Scott, 1982) [DVD. España: Warner Bros Entertainment]

En esta percepción, y el cambio que supuso a nivel tecnológico, debemos contemplar un último punto: los anteriormente mencionados procesos de aceleración tecnológico-temporal, de los que el "presente-pasado" como idea de futuro en las producciones ciberpunk parece haberse convertido en paradigma.

Como Robert Hewison apunta en su análisis de las aproximaciones postapocalípticas de Derek Jarman en The Last of England (1987), la ruptura de los tiempos históricos propia del momento no sólo se ha llevado tras de sí el pasado, sino, sobre 
todo, el futuro. Es en esta reflexión en la que las ficciones ciberpunks pueden servir como reflejo, crítica y consideración filosófico-histórica del "momento" — mejor cabría decir "situación", para ser fieles a la negación temporal- No es extraño, por tanto, que el propio autor titule su obra, elocuentemente, como Future Tense, jugando tanto con la conjugación verbal como con la tensión del momento acerca de la propia idea de futuro, eliminada por el nuevo paradigma hiperreal impuesto por la aceleración económico-tecnológica.

\section{Conclusión: nuevos paradigmas estéticos, nuevos paradigmas históricos}

Efectivamente, como indica Harvey, todo cambio convulso de tiempo produce inevitablemente una reformulación sensible que se traduce en el ámbito de la estética. Si a ello sumamos esta propuesta de Hewison tendremos que en un tiempo en que la "realidad" se ha disuelto en la imagen hiperreal y el simulacro, tal vez sea, precisamente a la ficción y el arte donde haya que recurrir para poder entender nuestro propio tiempo.

En este caso, no parece necesario retomar argumentos como los de Hal Foster acerca del "retorno de lo real" (Foster, 2001) para una nueva comprensión de la realidad a través de fenómenos estéticos como los espacios profílmicos del ciberpunk. Precisamente, no es lo real en si lo que parece haberse perdido, sino la idea de realidad que, como en Matrix, ha sido sustituida por otra mediante inducción tecnológica. No es de extrañar, por tanto, que sea entonces la ficción y su investigación prospectiva quien hoy en día parezca hablar más de la realidad que la realidad misma, desaparecida está en la propia ficción.

El género ciberpunk se convierte así en algo más que un estilo al uso, en el que entre sus características se encuentra la preocupación temporal distópica. El tiempo se introduce en sus tramas como reflejo del propio tiempo en el que dichas producciones vieron la luz, asistiendo a una nueva creación de la idea de futuro que, como indica "Bifo" Berardi, "no es una dimensión natural de la mente humana, es una modalidad de percepción y de imaginación y una modalidad de espera y de expansión. Y esta modalidad se transforma a lo largo de la historia" (Berardi, 2014: 40).

La insistencia en un futuro hipertecnológico, desigual en lo social y totalitario en lo político, donde la humanidad ha sucumbido víctima de la alienación y en la que toda la información está siendo creada como estrategia de control, no resulta lejana desde los años posteriores al 2019 en que se situaba Blade Runner. Quizá, incluso, esa ruptura temporal e histórica que aquí queríamos observar, y que en las producciones analizadas se concretaba en una referencia espacial al pasado, no sea otra cosa que el aviso de esa nueva "edad oscura", hipertecnologizada y acelerada, en la que vivimos actualmente en un presente-futuro realmente postapocalíptico (Bridle, 2020). Un nuevo tiempo en el que, como advertía Benjamin (2008: 47) hasta el arte, la ficción y la imaginación contribuyen, al hilo de los tiempos, a mostrarnos nuestra propia destrucción como un goce estético de primera categoría.

El ciberpunk, por tanto, con sus investigaciones prospectivas en los espacios profílmicos que configuran, se convierte así no sólo en el emblema del "tiempo sin tiempo" propio de la posmodernidad y sus mutaciones sensibles, sino incluso, y volviendo sobre los argumentos de Zizek, en la destrucción de una realidad incapaz de imaginar ya la utopía: 
Hasta la llegada de la posmodernidad, la utopía tenía por misión la huida de lo real de la historia hacia una Otredad intemporal. Con la llegada de la época en la que coinciden el "fin de la historia" posmoderno y la plena disponibilidad del pasado en un recuerdo digitalizado, de una época en la que todos VIVIMOS la utopía intemporal como una experiencia ideológica cotidiana, la utopía pasa a ser la aspiración a lo Real mismo de la Historia, del recuerdo, de la marca del pasado, el intento de salir de la burbuja hacia el hedor y la podredumbre de la realidad en bruto. Matrix da el último giro a esta inversión, al combinar la utopía con la distopía: la realidad misma en la que vivimos, la utopía intemporal representada por Matrix, tiene realmente por objeto reducirnos al estado pasivo de bacterias vivientes para proporcionarle energía a Matrix. (Zizek, 2006: 198)

Es en este sentido en el que, según hemos tratado de analizar y defender, el ciberpunk, con sus hoy en día reconocibles características profílmicas en la representación de distopías temporales, representa algo que va mucho más allá de un género cinematográfico e incluso del pastiche propio de la posmodernidad. La existencia de esas características hoy plenamente definidas, y que ejemplos como los aquí analizados representan a la perfección en sus implicaciones sociales, políticas e incluso epistemológicas en la comprensión actual de la configuración de la realidad, suponen ser un buen ejemplo de estética modal. Elementos de ficción a través de la que no sólo se analizan, sino se ensayan, las transformaciones futuras de una sociedad, por medio del recurso a la filosofía de la historia y de los medios, en la construcción de los espacios profílmicos de estas producciones de investigación prospectiva en los espacios de la ciencia-ficción.

\section{Bibliografía}

Anderson, P. (1992) Los fines de la historia. Barcelona: Anagrama.

Augé, M. (2017) Los no-lugares. Espacios del anonimato. Barcelona: Gedisa.

Avanessian, A y Reis, M (ed.) (2017) Aceleracionismo. Estrategias para una transición al postcapitalismo. Buenos Aires: Caja Negra.

Baudrillard, J. (1978) Cultura y simulacro (Traducción de Pedro Rovira). Barcelona, Kairós.

Benjamin, W. (2008) "La obra de arte en la época de su reproductibilidad técnica", Obras I, vol 2, pp 11-47. Madrid: Abada.

Berardi, F. (2014) Después del futuro.Desde el futurismo al ciberpunk, el agotamiento de la modernidad. Madrid: Enclave de Libros.

Berruezo, P. y Catalina, D. (2004) Dentro de Matrix. Palma de Mallorca: Dolmen.

Bridle, J. (2020) La nueva edad oscura. La tecnología y el fin del futuro. Barcelona: Debate. Certeau, M. (2008) “Andar la ciudad”, Bifurcaciones: revista de estudios culturales urbanos, $N^{o}$. 7, 2008. Recuperado de http://www.bifurcaciones.cl/007/reserva.htm (Fecha de acceso: $23 / 04 / 2021)$

Chandler, D. (1995). Technological or Media Determinism. Recuperado de http://visualmemory.co.uk/daniel/Documents/tecdet/ (Fecha de acceso 16/02/2021)

Claramonte, J. (2016) Estética modal. Madrid: Tecnos.

Crary, J. (2008) Las técnicas del observador. Visión y modernidad en el siglo XIX. Murcia: CENDEAC.

Darke, C. (2005) Alphaville. Londres: I. B. Tauris.

Debord, G. (1999) La Sociedad del Espectáculo. Valencia: Pre-textos. 
Foster, H. (2001) El retorno de lo real. La vanguardia a finales de siglo. Madrid: Akal.

Fukuyama, F (1990) “¿El fin de la historia?”. Claves de la razón práctica, 1 (abril 1990), pp 85-96.

Gordon, A. (2005) "Matrix: ¿paradigma del posmodernismo o afectación intelectual?" en Yeffeth, Glenn (ed.) Tomar la pastilla roja. Ciencia, filosofía y religión en Matrix. Barcelona: Ediciones Obelisco, pp 103-124.

Habermas, J. (1989) El discurso filosófico de la modernidad. Madrid, Taurus.

Harvey, D. (2017) La condición de la posmodernidad. Investigación sobre los orígenes del cambio cultural. Buenos Aires: Amorrortu.

Hewison, R. (1990) Future Tense: A New Art for the Nineties. Londres: Methuen.

Jameson, F. (2009) Arqueologías de futuro. El deseo llamado utopía y otras aproximaciones de ciencia ficción. Madrid: Akal.

Kant, I (2018) Crítica de la razón pura. Madrid: Gredos.

Kern, S. (2003) The Culture of Time and Space. Harvard University Press.

Koselleck, R (1993) Futuro pasado. Para una semántica de los tiempos históricos. Barcelona: Paidós.

Latorre, J.M. (1994) Blade Runner/Amarcord. Barcelona: Libros Dirigido Por.

Marquard, O. (2000) "Historia universal e historia multiversal", Apología de lo contingente, Institució Alfons el Magnánim Valencia, pp. 69-88.

Muñoz, J. (2010) Filosofía de la historia. Origen y desarrollo de la conciencia histórica. Madrid: Biblioteca Nueva.

Noys, B (2018) Velocidades malignas. Aceleracionismo y capitalismo. Segovia: Materia Oscura.

Nunn, Samuel. (2001) "Diseñando la ciudad solipsista: Temas de planeamiento urbano y control en Matrix, Dark City y el show de Truman". DC Papers. Revista de crítica $i$ teoria de l'arquitectura, 2001, Núm.5 Recuperado de https://www.raco.cat/index.php/ DC/article/view/84009 (Fecha de acceso 16/10/2019)

Plant, S. (2008) El gesto más radical. La Internacional Situacionista en una época postmoderna. Madrid: Errata Naturae.

Rancière, J. (2014) El reparto de lo sensible. Estética y política. Buenos Aires: Prometeo.

Sammon, P. M. (2005) Futuro en negro. Madrid: Imágica.

Schaeffer, J-M. (2002) ¿Por qué la ficción? Madrid: Lengua de Trapo.

Stiegler, B (2004) La técnica y el tiempo. Vol III: El tiempo del cine y la cuestión del malestar. Hondarribia: Hiru.

Taylor, B. (1987) Modernism, Postmodernism, Realism: A Critical Perspective for Art. Whinchester School of Arts.

Valle Corpas, I. (2018). "Memento vivere o cómo escapar de Alphaville. Algunas notas sobre Godard y el situacionismo". Escritura E Imagen,14, 9-27. Recuperado de https://doi. org/10.5209/ESIM.62758 (Fecha de acceso 21/01/2020)

Váttimo, G. (1991) "Postmodernidad y fin de la historia", Ética de la interpretación, Paidós, Barcelona, 1991, pp 15-35.

Vilar, G. (2021) Disturbios de la razón. La investigación artística. Madrid: Antonio Machado. White, H. (1980) "The Value of Narrativity in the Representation of Reality", On Narrative. Critical Inquiry, 7, vol 1(otoño 1980), pp 5-27.

Zizek, S (2000) "The Matrix, o las dos caras de la perversión" (Traducción de Carolina Díaz), Acción paralela, ${ }^{\circ}$ 5. Recuperado de https://www.anticapitalistas.org/IMG/pdf/ Zizek-TheMatrixOLasDosCarasDeLaPerversion.pdf (Fecha de acceso:14/09/2021)

Zizek, S. (2006) Lacrimaer Rerum: ensayos sobre cine moderno y ciberespacio. Barcelona: Debate. 